\title{
Video clips for YouTube: Collaborative video creation as an educational concept for knowledge acquisition and attitude change related to obesity stigmatization
}

\author{
Carmen Zahn • Norbert Schaeffeler • \\ Katrin Elisabeth Giel • Daniel Wessel • \\ Ansgar Thiel • Stephan Zipfel • Friedrich W. Hesse
}

Published online: 19 September 2013

(C) Springer Science+Business Media New York 2013

\begin{abstract}
Mobile phones and advanced web-based video tools have pushed forward new paradigms for using video in education: Today, students can readily create and broadcast their own digital videos for others and create entirely new patterns of video-based information structures for modern online-communities and multimedia environments. This paradigm shift in video usage can be used for advanced learning about complex topics in higher education, for example, learning about socio-scientific or medical topics. Yet-technology aside-applicable educational concepts using collaborative video creation as a method need to be developed. In the present study, we investigate a specific concept
\end{abstract}

\section{Zahn $(\bowtie)$}

University of Applied Sciences and Arts Northwestern Switzerland, Riggenbachstrasse 16, 4600 Olten, Switzerland e-mail: carmen.zahn@fhnw.ch

N. Schaeffeler $\cdot$ K. E. Giel $\cdot$ S. Zipfel

Department of Psychosomatic Medicine and Psychotherapy, University Hospital of Tuebingen, University Medical Hospital of Tuebingen, Osianderstrasse 5, 72076 Tuebingen, Germany

\section{N. Schaeffeler}

e-mail: norbert.schaeffeler@med.uni-tuebingen.de

K. E. Giel

e-mail: katrin.giel@med.uni-tuebingen.de

S. Zipfel

e-mail: stephan.zipfel@med.uni-tuebingen.de

D. Wessel • F. W. Hesse

Knowledge Media Research Center, Schleichstrasse 6, 72076 Tuebingen, Germany

D. Wessel

e-mail: d.wessel@iwm-kmrc.de

\section{A. Thiel}

University of Tuebingen, Wilhelmstrasse 124, 72074 Tuebingen, Germany

e-mail: ansgar.thiel@uni-tuebingen.de 
designed to fight obesity stigmatization by developing knowledge using a learningthrough-design-approach. We expected that creating videos can actually contribute to a deeper understanding of obesity and to a reduction in stigmatizing attitudes-when compared to a control condition. Dependent measures were based on the students' video products, obesity-related knowledge and attitudes. The course group assessed their own knowledge on causes of obesity and stigmatization because of obesity higher in the posttest than a control group who read a newspaper article on the topic. A corresponding significant reduction in stigmatizing attitudes was found. In sum, results indicate significant differences between students who produced YouTube videos and a control group of students. The results are interpreted as a confirmation of our initial assumptions and evidence indicating that the program is successfully applicable in higher education.

Keywords Video - Mobile learning - Authorship and creativity · Education · Health . Obesity $\cdot$ Socio-scientific topics

\section{Introduction}

Today, students of almost all age groups use mobile phones and advanced digital video tools to create and broadcast their own digital videos for others. They can design complex information structures based on video, or post comments and 'video responses' on video platforms such as 'YouTube' (Burgess and Green 2009; Cha et al. 2007; Jenkins 2009). In other words: Students can create entirely new patterns of video-based information structures for modern online-communities and emerging multimedia environments (Alby 2007).

This paradigm shift in video usage (Burgess and Green 2009) was studied for learning purposes in previous research for advanced arts and literature studies, and natural science learning (Pea et al. 2004), for video research and video collaboration (Pea and Hoffert 2007), and for history learning in school-based education (Zahn et al. 2010a, b, 2012). This research has specified on the theoretical and empirical level how advanced activities of designing video-based information structures differ from more traditional forms of video usage in educational settings and how they provide high potentials for collaborative learning and for constructive learning in activity (e.g., Greeno 2006). Collaborative learner activities are important in educational settings, because participation in peer interaction can facilitate and stimulate cognitive elaboration in a number of different ways, as was summarized in earlier research literature (e.g., Webb and Palincsar 1996): Not only can peers give information, help and explanations to a learner, but there are a variety of learning mechanisms stimulated by peer interaction: First, peer interactions can induce joint meaning making, the construction of shared meanings and conceptual convergence in collaborative problem solving (e.g., Roschelle 1992). Second, when peers do not agree on a topic, theory or opinion, cognitive conflicts can arise during peer interaction and learners may negotiate meaning, and search for additional information thereby elaborating on a deeper level in order to solve their cognitive conflicts (Piaget, 1985 cited in Webb and Palincsar 1996). Third, participation in peer interaction can facilitate the internalization of social processes and cultural practice (like talking in a new language or argumenting in a discussion), as important individual 
skills (Vygotsky, 1979 cited in Webb and Palincsar 1996). Fourth, peers can act as models and lead to learning and skills acquisition by observation (e.g., Bandura, 1985, cited in Webb and Palincsar 1996). Fifth, peers can be a strong motivator for enhanced joint mental effort during learning, when external goal structures exist (e.g., Slavin, 1983; Johnson \& Johnson, 1985; cited in Webb and Palincsar 1996). Finally, peer interaction can be a "communication" goal supporting learning: for instance, designing a presentation for other peers (or a broad audience) is at its core a form of complex problem solving (Goel and Pirolli 1992), where problem solving activities shape important knowledge transformation processes, and ultimately, learning (Bereiter and Scardamalia 1987; Kafai 1996).

In the present contribution we focus on this latter form of collaborative learning: Designing for an audience-in our case student teams producing a video clip. We developed earlier an educational concept for such constructivist video usage based on the paradigm shift associated with mobile phones and easy to use web-based video tools that provides new potentials for implementing constructivist design approaches to learning in schools, higher education and teacher training (which we labelled collaborative visual design Zahn et al. 2009, 2010a; Krauskopf et al. 2012).

In this article here, we report on a field experiment investigating whether the collaborative visual design approach can also be leveraged to change attitudes towards complex societal topics, which are often a learning goal in higher education. Specifically, we investigate the research question: How can we use video creation (here: video clips for YouTube) in psychology studies to support learners in developing knowledge (here: concerning obesity) and reduce potential stigmatizing tendencies (here: related to obese people)?

In order to answer this question, we tested a course concept described below using collaborative visual design as a method to fight obesity stigmatization (for details on obesity stigmatization, see Degner and Wentura 2005). The course concept is based on two basic assumptions derived from social psychology research and from research in the learning sciences:

1. Stigmatization of obese people is partly based on knowledge gaps, misconceptions and oversimplifications concerning the complex nature of obesity.

2. Learning through collaborative visual design (e.g. producing YouTube video clips) is an appropriate method that contributes to a deeper understanding of the complexity of societal topics (such as obesity), and therefore can lead to a reduction in stigmatizing attitudes.

In the next section we will provide the theoretical background concerning these assumptions and then provide initial empirical results from our field study.

\section{Theoretical background}

\subsection{Obesity stigmatization}

Obesity is currently one of the most prevalent and challenging public health issues among industrialized countries (Baur 2001; Mensink et al. 2012; Preiss et al. 2013). The World Health Organization has described it as a "global epidemic" 
(see http://www.who.int/nutrition/topics/obesity/en/). The causal relations underlying obesity and its consequences are manifold and difficult to understand (Haslam and James 2005). Yet, we do know that obesity stigmatization in our society adds to the severity of the problem: Stigmatisation of obese people does not only occur in private live, but also in work settings and health systems with devastating consequences for obese people, because being a severe stressor it threatens health, both mental and somatic, and is an obstacle to effective prevention and treatment (e.g., Giel et al. 2010; Gaebel et al. 2010; Persky and Eccleston 2010; Puhl and Brownell 2001; Puhl and Heuer 2010; Sikorski et al. 2011; Giel et al. 2012) as well as in the media (Hilbert and Ried 2009; Hussin et al. 2011; Ata and Thompson 2010).

Stigmatizing attitudes spread, because, for example, the media steadily reinforce misconceptions and oversimplifications that lead to prejudice (Ata and Thompson 2010) such as the widespread opinion "obese could easily control their eating behaviours and lose weight, if they had more discipline" - a very prevalent misconception and oversimplification. In order to fight stigmatization, projects have tried to reduce stigma by providing information and fostering learning and acquisition of a better understanding of the topic and the affected people (Gaebel et al. 2010). Social psychological research on stereotypes about obese people has repeatedly demonstrated in controlled lab studies that stigmatizing attitudes related to obesity can actually be improved by providing causal information (Puhl et al. 2005; Teachman et al. 2003). However, caution is warranted in generalizing such results: From a learning sciences perspective we know that changing misconceptions and supporting a deep understanding of complex subject matter "outside the lab" is not easy and simply giving information in a flyer or on a website does not necessarily lead to better understanding-nor are single instructional strategies of lecturing, reading or viewing audiovisual information materials (for an extensive review on the effectiveness of antistigmatization methods see Gaebel et al. 2010). According to Bloom's taxonomy (1956; Anderson and Krathwohl 2001) we assume here that the goals of reducing stigmatizing attitudes and developing a deep understanding of the complex causal relations in obesity simultaneously address different domains of learning at cognitive, attitudinal and skills levels. These levels are targeted by student-centered teaching strategies, such as problembased learning or learning through design (Kafai and Resnick 1996). Our specific educational approach, which we applied and tested in a study is described in the next section.

\subsection{The educational concept-video creation as a method}

Why do we assume that producing YouTube video clips might be a promising strategy that contributes to a deeper understanding of the complexity of societal topics such as obesity stigmatization, and therefore can lead to a reduction in stigmatizing attitudes? Explanations for this benefit can be ascribed to two aspects: First, using video as a collaborative tool and second, the collaborative design process.

Concerning video, Schwartz and Hartman (2007) describe comprehensively the "space of learning for the use of designed video" (p. 338). Literature on video authorship for learning covers areas such as personal agency, self-efficacy and collective efficacy (e.g., Bandura 2004a) precisely in the area of health promotion efforts (Bandura 2004b; Chavez et al. 2004). Cognitive-constructivist frameworks for the use of video in the social science classroom demonstrate how to support perspectivity and critical analysis using video authoring tools (Goldman 2004, 2007). Recent approaches have turned to 
comprehensively investigating video tools used for complex design tasks (similar to the learning through design approach, e.g., Kafai and Resnick 1996) where students arrange video contents in order to learn.

Concerning collaborative design, specific components of design leverage deep learning and the possible attitude shifts we address here. What are those elements of design? Generally, design is seen as complex problem solving (Goel and Pirolli 1992). When students design, they are asked to reformulate their knowledge for an audience (Harel 1990; Hayes 1996; Kafai and Ching 2001; Kafai 1996; Kolodner et al. 2003a, b), for instance, when designing a model, learners apply science concepts and science laws to physical objects or when constructing hypermedia, learners translate their topic-related ideas using a "hyper" structure for interactively dynamic sequences of texts and pictures (Lehrer et al. 1994). As a collaborative activity (Hennessey and Murphy 1999; Maldonado et al. 2007), design creates a demand for students to negotiate meaning in a design team, to achieve common ground about design goals and design content when they make their design decisions, taking into consideration anticipated audience, intended "message," and the constraints of their available technologies. In this process, students can express and defend (or change) their own understanding of a topic. They can also reflect on their own and their collaborators' knowledge or opinions in design discussions. They thus are expected to acquire knowledge, thinking skills, problem solving skills, and communication skills during these design activities including skills of critical analysis and media literacy (e.g., design skills, Carver et al. 1992; new media skills, Jenkins et al. 2006).

Figure 1 summarizes the specific design problem solving activities that are assumed to shape such knowledge transformation processes, and ultimately, learning, based on an approach to hypermedia design by Lehrer et al. (1994).

Yet learning through design cannot be taken for granted. Individual and collaborative achievements in design problems depend centrally on social and physical task environments that interact with individual cognition of the participating individuals. This was evidenced with samples of school-students who needed instructional

\begin{tabular}{|ll|ll|}
\hline $\begin{array}{l}\text { Inquiry on a specific } \\
\text { content area } \\
\text { and understand the } \\
\text { interrelations }\end{array}$ & $\begin{array}{l}\text { Reflect critically on } \\
\text { pieces of information } \\
\text { their sources, develop } \\
\text { new ideas }\end{array}$ & $\begin{array}{l}\text { Ask for feedback, discuss } \\
\text { preliminary product with } \\
\text { others }\end{array}$ & $\begin{array}{l}\text { Integrate feedback, } \\
\text { realize own mistakes, } \\
\text { correct misconceptions }\end{array}$ \\
\hline \multicolumn{1}{|c|}{ Planning } & Transformation & Evaluation & Revision \\
\hline $\begin{array}{l}\text { Anticipate future } \\
\text { audience, set rhetoric } \\
\text { goals, select pieces of } \\
\text { information, understand } \\
\text { software functions }\end{array}$ & $\begin{array}{l}\text { Explicate (visually and } \\
\text { verbally) own knowledge } \\
\text { and available } \\
\text { information in media } \\
\text { product for anticipated } \\
\text { audience }\end{array}$ & $\begin{array}{l}\text { Substantiate one's own } \\
\text { rhetoric goals and argue } \\
\text { for them }\end{array}$ & $\begin{array}{l}\text { Re-formulate own } \\
\text { knowledge and available } \\
\text { information }\end{array}$ \\
\hline
\end{tabular}

Fig. 1 Cognitive and socio-cognitive activities during collaborative design problem solving 
guidance in design for successful performance and learning (Zahn et al. 2010b, 2012) and with students in university courses where specific programs for video authorship are needed as instructional support (e.g., Stahl et al. 2006a, b).

In our present endeavour, we adapted a student-centered learning program that is based on the principles of video authoring as a method of teaching and learning (collaborative visual design, Zahn et al. 2010a) and the above mentioned previous experimental and field study results. In our adaptation of the program for the obesity topic, the goal of the course was twofold: We targeted the understanding of obesity and stigmatizing attitudes. Knowledge communication with social video tools and stigmatization in the media was addressed, too. The video clips production for YouTube was supported in our course in several phases: First, research on media and stigmatization, second, theory approaches and concepts relating to obesity, third, video production (writing an exposé, writing a storyline, designing a storyboard, capturing and editing the video), and finally, reflection of learning and the video product. Each phase lasted several weeks (see below) with weekly meetings (one per week each lasting $90 \mathrm{~min}$ ). The phases will be described in detail in the following paragraphs and are shown in Fig. 2.

\subsubsection{Research phase (weeks 1-3): Media-related knowledge acquisition}

During the research phase students were provided with a course introduction, the course program and deadlines. The students selected sub-topics (see below) and divided themselves into small groups to work together for the rest of the semester. Technology was introduced: a course wiki providing all organizational information, literature and the course structure and serving as an exchange platform for collaboration (see Fig. 3) and several video editing tools. Moreover, the students analysed the YouTube platform in order to become familiar with it. They analyzed the functions of YouTube, the "genre" of YouTube clips, and how YouTube contributes as a social "Web 2.0" medium (Burgess and Green 2009) to knowledge building (Scardamalia and Bereiter 2002). In particular, students analysed how the topic of obesity is dealt with (e.g., informative videos about obesity vs. "fun" video clips of obese people, video user ratings and user comments) with respect to stigmatization in the media (Ata and Thompson 2010).

\subsubsection{Theory phase (weeks 4-8): Content knowledge acquisition}

During the theory phase, the student groups deepened their knowledge on their selected sub-topics based on the provided literature (on: obesity prevalence, distribution, causal factors and development, comorbidity, treatments, prevention, positive and negative attitudes, and stigmatization). Then students presented for their fellow

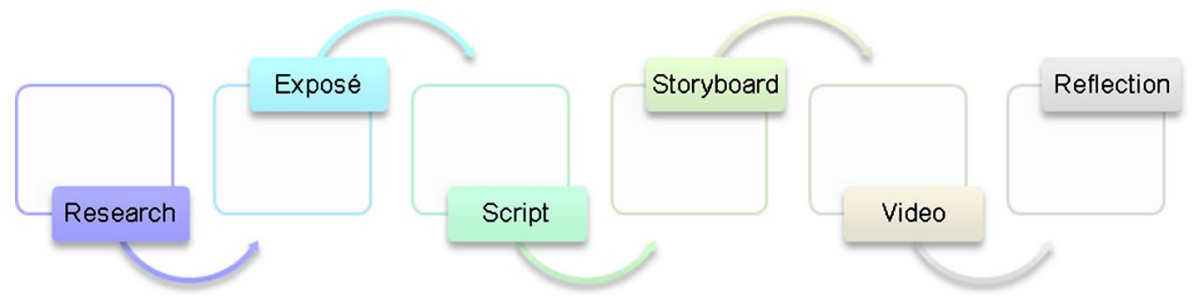

Fig. 2 Phases of the course program 


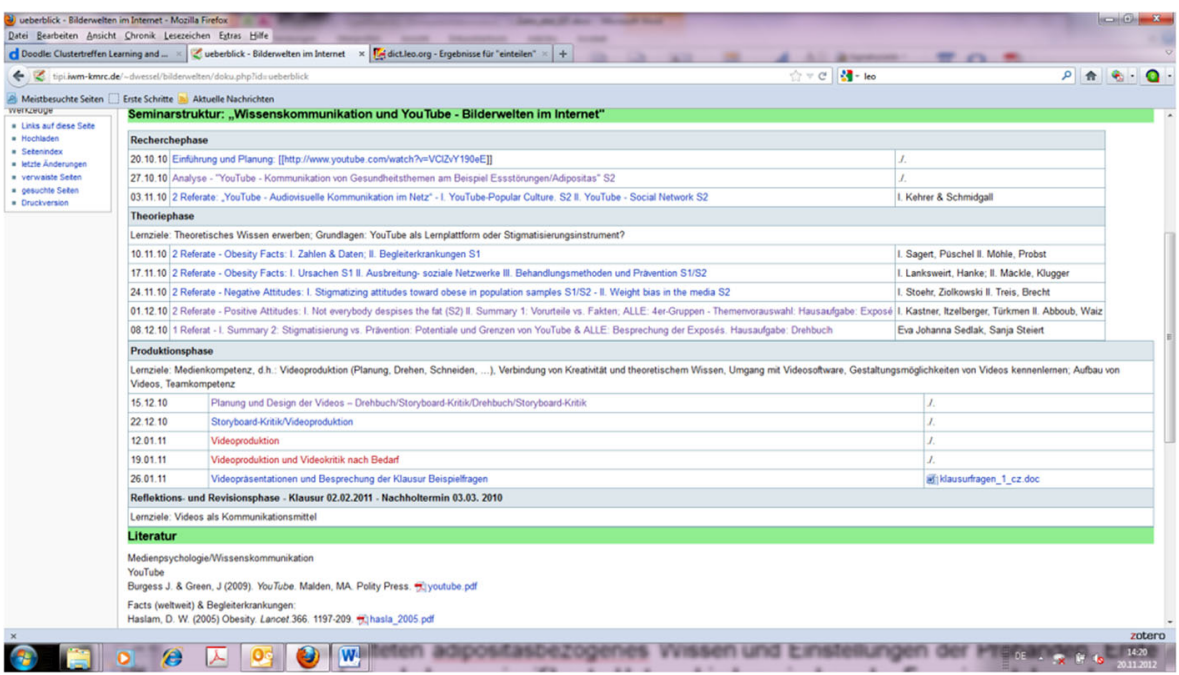

Fig. 3 The course wiki providing for course information and literature and displaying the course structure

students in the course, respectively. Each group gave a talk on their sub-topic and discussed the central concepts and open questions with the whole course.

\subsubsection{Video production phase (weeks 8-12): Knowledge transformation}

During the video production phase, the students were asked to transform their knowledge on their selected sub-topic into a video clip. They were free to select filmic style and features, yet adherence to ethical rules and to YouTube conventions were required. Maximum length of the video clips was restricted to about 4-5 min. The video production phase was supported and structured by the teacher providing separate sub-tasks to support students in the collaborative process: writing an exposé and developing a time schedule (week 8), writing a script (week 9), designing a storyboard (week 10), capturing and editing the video clip (weeks 10-12), presenting and discussing the video clip (week 12). The teacher had a moderating role during these tasks and provided for help when needed and continuous feedback.

For the exposé, students were asked to write a one page summary briefly describing the goal, the target audience, the message, the genre and the overall dramaturgy of their video clip including first ideas concerning style and features (e.g., cartoon, documentary, music clip, symbols, etc.). For the time schedule, students were asked to set their own group deadlines while adhering to the deadlines given by the course structure and to organize their collaboration (e.g., talk about roles and possible divisions of labour). Feedback on the exposés and time schedules was then given by the teacher to each group.

For the script, students received an excerpt from a professional movie script as an example and they were asked to produce a script from their own exposés based on the feedback. They should thereby further specify the concrete realization of their video clip including detailed descriptions of the pictures and possibly dialogues or music. Feedback, again, was then given by the teacher to each group. 
For the storyboard, again a professional example was provided, but the students chose their favourite visualization types by themselves and according to their skills (drawings, sketches, photos). Students were asked to transform their own text-based scripts into a detailed storyboard illustrating (not only describing) each single image (shot) of the future video clip. The teacher gave detailed feedback on the accomplishment of this task, as well.

Video production including capturing and editing according to the storyboards was based on the storyboards and the respective feedback and then self-organized by the groups. The teacher assisted in showing how to use the cameras and video editing tools if necessary.

\subsubsection{Reflection phase (week 13): Self-evaluation and feedback}

The reflection phase consisted of finally presenting the video clip in the last meeting of the course (week 13) a final exam (extra meeting) and a course evaluation. At the final presentation of the video clip by groups, immediate feedback was given to each video by the fellow students in the course. Afterwards the teacher gave her feedback separately to each group. The final exam was written individually and consisted of a video product analysis (of the group's product) and a reflection of the production process. Course evaluation was based on a short questionnaire to be filled in by the students (anonymous distributed and analyzed by the university administration, summary provided to the teacher).

For the purpose of our study described in the following section, a questionnaire measuring knowledge and attitudes towards obese people was provided, too, after the final exams. The questionnaire was independent of the course and final exam and anonymous and voluntary. In order to ensure voluntary participation, the teacher left the room before distribution of the questionnaire by an experimenter.

\section{The study}

\subsection{Participants}

In total, 53 psychology students took part in this study. Baseline measures were surveyed at start of the summer term (t0). Three out of the course group and four out of the control group did not take part at the end of term ( $\mathrm{t} 1)$. The course group was a sample of students who attended a module in applied cognitive and media psychology. The control group was recruited by a flyer asking for psychology students who would like to participate in a study for participation credits and were not enrolled in the course.

\subsection{Quasi-experimental design and procedure}

The study design was quasi-experimental in the sense that the whole course group was compared to controls instead of randomly allocating them to the different conditions. The students chose our "experimental" course condition within their real study context. The local ethics committee approved our study design. 
We asked all participants in our study to fill in a questionnaire-package (see below) at two points in time: One at the beginning of the summer semester ( $\mathrm{t} 0$ ) and 3 months later at the end (t1). In between, the course group participated in the course module in which they were asked to produce a short video clip about obesity. The production process followed exactly the concept described above (p. $5 \mathrm{ff}$ ). For their video clips, they could choose specific content during the research phase from an array of subtopics including obesity prevalence, distribution, causal factors and development, comorbidity, treatments, prevention, positive and negative attitudes, and stigmatization. Students used their own mobile phones, cameras or devices provided by teacher. Teachers provided support in case of any technology-related problems, yet there were no problems with implementing technology into the course. The control group read a current randomly chosen newspaper-article entitled "Menschen, die alles dicke haben" ["People who are fed up with everything"] (Süddeutsche Zeitung, 2010) after measuring baseline data at 0 . Both groups were otherwise exposed to the ongoing everyday public discussion on obesity in the media. The newspaper article was provided for the controls to enhance fairness of testing between the conditions. The article contained detailed information about obesity for the control group, too, so that they had a chance to learn about the topic through reading the article, and were possibly primed to the discussion in the media (similar to the course group).

\subsection{General hypothesis}

We assumed that the course group-learning by creating video clips-would acquire a substantial body of knowledge about obesity and stigmatization between $\mathrm{t} 0$ and $\mathrm{t} 1$. In particular, we expected them to develop a good understanding about the complexity of causal factors and relations in development of obesity and about sub-topics according to the course learning goals. In contrast to the course group, we expected the control group who read the article and had other possible input by the public media to learn less and know less at $\mathrm{t} 1$. At the same time, we expected the stigmatization tendency of the course group to decrease in comparison to the control group due to the development of new knowledge about obesity.

\subsection{Course context}

The study took place at a German University during the summer semester lasting for about 3 months. Our course was offered as a module in the area of applied cognitive and media psychology, which did not immediately hint to the context of obesity and stigmatization.

\subsection{Measures}

In order to assess possible changes in knowledge and stigmatization tendencies/attitudes over the course of the semester (from t0 to t1), we applied a questionnaire-package based on standardized measures for obesity-related attitudes and stigmatization tendencies (such as Degner's, 2006 stigmatization scale), and related control variables (e.g., self-assessment of own body, and body mass index). We added to the questionnaire two types of knowledge assessments: self-assessments of how knowledgeable on obesity students rated themselves 
(subjective measures) and knowledge questions about the causes of obesity (objective measures). In sum, the participants' knowledge acquisition about obesity topics and their tendency for stigmatizing obese people were assessed.

Self-acceptance As a control variable, we measured self-acceptance of the own body. We used a body concept measure (6-item-subscale Frankfurt Body Concept Scale [SSAK, Frankfurter Körperkonzeptskalen (FKKS-6), Deusinger 1998) and a measure for strive to thinness (7-item-subscale Thrive to Thinness [Schlankheitsstreben] of the eating-disorder-inventory EDI-2, Paul and Thiel 2005). We asked the students to note their actual, least and ultimate weight as well as their height, satisfaction with their weight ( 6 categories from very unsatisfied to very satisfied) and their own and others assessment of their body mass in 7 categories from "strong underweight" to "strong overweight" (see Degner 2006).

Knowledge about obesity As a subjective knowledge measure, students were asked to assess their state of knowledge about somatic and psychic factors influencing development and maintenance of overweight, comorbidity, consequences, and stigmatization because of obesity and weight loss methods on a 7 step Likert scale (Example item: "Please indicate your knowledge about obesity stigmatization on the following scale.", see Table 1). As an objective measure, two open questions asked for known somatic and psychic factors, which cause and maintain overweight. The answers to the knowledge questions were coded by two independent and trained raters according to the coding scheme shown in Table 2 for correct obesity-related concepts, misconceptions and correct use of technical terms. The interrater-consistency was high (Cronbach's Alpha between .928 and 1.000). One further expert rater (medical expert) counted the number of technical terms (correct use of technical terms only).

Stigmatization tendency and attitudes toward obesity The measure of stigmatization tendency consisted of a combined German questionnaire for the assessment of attitudes related to obese persons on a 7 step Likert scale ("Fragebogen zur Erfassung von Einstellungen gegenüber übergewichtigen Menschen" [Questionnaire for Measurement of Attitudes toward Obese People], Degner 2006). This questionnaire consists of 30 items forming the dimensions "refusal and contact shunning" (11 items), "assignment of guilt" (7 items), "fat phobia" (3 items), "feature of performance" (6 items) and "responsibility

Table 1 Self-assessment of knowledge about obesity (1-7 Likert Scale): "Please indicate how you would rate your knowledge about the following topics"
Knowledge items:

1) Development of obesity somatic factors

2) Development of obesity psychic factors

3) Maintaining factors of obesity

4) Somatic comorbidity

5) Mental comorbidity

6) Consequences obesity

7) Stigmatization because of obesity

8) Weight loss methods: dieting, conducted weight loss programs

9) Surgical weight loss methods 
Table 2 Coding scheme for assessment of knowledge about obesity from answers to open question 7-10: "Which somatic or psychic factors do you know of that cause obesity?"

\begin{tabular}{|c|c|c|}
\hline Category & Description & Examples \\
\hline \multicolumn{3}{|l|}{ Psychic factors } \\
\hline Concepts & $\begin{array}{l}\text { Psychic factors which cause or } \\
\text { maintain overweight }\end{array}$ & $\begin{array}{l}\text { "Stigmatisation" } \\
\text { "Socialisation" } \\
\text { "Mental disorder" } \\
\text { "Lack of coping strategies" }\end{array}$ \\
\hline Misconceptions & Wrong answers & $\begin{array}{l}\text { "Food jealousy" } \\
\text { "Substance abuse" }\end{array}$ \\
\hline Domain specific technical terms & & $\begin{array}{l}\text { "Eating disorder" } \\
\text { "Affect regulation" } \\
\text { "Modelling" } \\
\text { "Coping" }\end{array}$ \\
\hline \multicolumn{3}{|l|}{ Somatic factors } \\
\hline Category & Description & Examples \\
\hline Concepts & $\begin{array}{l}\text { Somatic factors which cause } \\
\text { or maintain overweight }\end{array}$ & $\begin{array}{l}\text { "Lack of exercise" } \\
\text { "Genetic disposition" } \\
\text { "Metabolic disorder" } \\
\text { "Medical treatment" }\end{array}$ \\
\hline Misconceptions & Wrong answers & $\begin{array}{l}\text { "No feeling of hunger" } \\
\text { "Food intolerance" }\end{array}$ \\
\hline Domain specific technical terms & & $\begin{array}{l}\text { "Metabolic disorder" } \\
\text { "Hypothyroidism" } \\
\text { "Hormonal balance" } \\
\text { "Energy balance" }\end{array}$ \\
\hline
\end{tabular}

for health" (3 items). Further 5 items focus on the influence of weight and attractiveness on the identity (Degner 2006; Wentura and Greve 2005). Apart from the total score, we particularly focus on the scale "assignment of guilt". This subscale measures whether a person considers obese people as being self-responsible for their obesity. Example items for this scale include: 2-17 "Nobody needs to be obese. Those who are overweight or obese, are self-responsible for being so", or: 2-21 "Obese people should contribute money to compensate for the costs they cause in public health systems". Based on our initial assumption (see above) we expect that developing knowledge about the complexity of causal relations in obesity should reduce the assignment of guilt, because the latter reflects an oversimplification of the topic.

\subsection{Data analyses}

All data was analysed with SPSS Statistics ${ }^{\circledR}$ 19.0. Demographic variables were analysed descriptively. To test differences between groups over time we used mixed between-within subjects analyses of variance. As this analysis is quite robust (Field 2005; Hays 1980) we trust in the calculated probability even if there is a significant Levene's Test and/or Box's Test. As this study has an explorative approach we did not correct the significance-level for multiple testing. 


\section{Results}

Group comparisons Table 3 shows sex, mean age, body mass index and satisfaction with own weight of our participants. The course group and control group did not differ significantly on these variables and no significant differences in our measures at t0 existed (all $p>.10$ ). None of the students had ever participated before in a course on obesity or a related topic or on a course performed with the video creation method.

Knowledge about obesity-subjective and objective measures In order to assess the differences in knowledge acquisition about aspects of obesity (subjective and objective measures, see Tables 1 and 2) from t0 to t1, we conducted mixed between-within subjects analyses of variance.

Self-assessed knowledge (subjective measure) Table 4 shows the means and standard deviations of self-assessed knowledge. Analyses of the self-assessments (see Table 7) yield significance on six from the nine variables with increasing values for the course group from to to tland compared to the control group: Concerning knowledge about somatic aspects in development of obesity a significant main effect for time $\left(F_{(1,44)}=\right.$ $4.7, p<.05)$ and an interaction for group $\mathrm{x}$ time $\left(F_{(1,44)}=5.4, p<.05\right)$ was found with increasing values for the course group from to to $\mathrm{t} 1$ and slightly decreasing values in the control group. Concerning knowledge about psychic factors in development of obesity a significant interaction group $\mathrm{x}$ time effect $\left(F_{(1,43)}=5.1, p<.05\right)$ was found with increasing values from to to $\mathrm{t} 1$ for the course group and decreasing values for the control group. Concerning knowledge about stigmatization highly significant effects were found for time $\left(F_{(1,43)}=9.1, p<.05\right)$, group $\left(F_{(1,43)}=13.8 ; p<.001\right)$ and group $\mathrm{x}$ time $\left(F_{(1,43)}=9.1, p<.05\right)$ with increasing values from to to $\mathrm{t} 1$ in the course group while the control group remained on exactly the same level. Concerning knowledge about mental comorbidities there was a significant main effect for group $\left(F_{(1,44)}=4.2, p<.05\right)$ with higher values of the course group at both times. There was a small increase of values for the course group and a small decrease for the control group. Concerning knowledge about somatic comorbidities a significant main effect was found for group $\left(F_{(1,43)}=10.3, p<.05\right)$ with higher values at both times for the course group suggesting more initial knowledge of the course group with only small increasing changes, and decreasing changes for the control group. Concerning knowledge of surgical weight loss methods a significant main effect for time

Table 3 Group comparisons of the two conditions (course vs. control group)

\begin{tabular}{|c|c|c|}
\hline & Course group $n=17$ & Control group $n=29$ \\
\hline Sex & $+15 \jmath^{\Uparrow} 2$ & $+25 \precsim 4$ \\
\hline Age & $23.5(\mathrm{SD} 1.9)$ & $22.3(\mathrm{SD} 3.8)$ \\
\hline Body mass index $\left(\mathrm{kg} / \mathrm{m}^{2}\right)$ & $21.1(\mathrm{SD} 1.6)$ & 20.7 (SD 2.2) \\
\hline Self-assessment of body mass & $4.1(\mathrm{SD} .6)$ & $4.0(\mathrm{SD} .7)$ \\
\hline Satisfaction with weight & $4.6(\mathrm{SD} 1.3)$ & 4.7 (SD 1.3) \\
\hline
\end{tabular}

Self-assessment of body mass ranging from 1 to 7 on a Likert Scale with $1=$ strong overweight and $7=$ strong underweight. Satisfaction with weight ranging from 1 to 6 on a Likert Scale with $1=$ very dissatisfied and $6=$ very satisfied 
Table 4 Means and standard deviations (SD) of self-assessed knowledge about aspects of obesity (subjective measure) in course and control group

\begin{tabular}{|c|c|c|c|c|c|c|}
\hline \multirow[t]{2}{*}{ Variable } & \multicolumn{3}{|c|}{ Seminar group } & \multicolumn{3}{|c|}{ Newspaper group } \\
\hline & $n$ & $\mathrm{t} 0 M(S D)$ & $\mathrm{t} 1 M(S D)$ & $n$ & $\mathrm{t} 0 M(S D)$ & $\mathrm{t} 1 M(S D)$ \\
\hline Development of obesity, somatic aspects & 17 & $4.2(1.33)$ & $5.1(1.05)$ & 29 & $4.5(1.27)$ & $4.4(1.15)$ \\
\hline Development of obesity, psychic aspects & 17 & $4.8(.90)$ & $5.1(1.17)$ & 29 & $4.89(1.26)$ & $4.2(1.18)$ \\
\hline Maintaining factors of obesity & 17 & $4.2(1.44)$ & $7.8(1.29)$ & 29 & $4.0(1.32)$ & $3.9(1.37)$ \\
\hline Somatic comorbidities & 17 & $4.9(1.22)$ & $5.3(.99)$ & 28 & $4.3(1.30)$ & $3.9(1.33)$ \\
\hline Mental comorbidities & 17 & $4.8(.97)$ & $5.2(.88)$ & 29 & $4.5(1.24)$ & $4.1(1.59)$ \\
\hline Consequences of obesity & 17 & $4.1(1.36)$ & $4.9(1.22)$ & 29 & $4.6(1.50)$ & $4.6(1.21)$ \\
\hline Stigmatization because of obesity & 17 & $4.5(1.13)$ & $5.8(1.03)$ & 28 & $3.8(1.52)$ & $3.8(1.48)$ \\
\hline Weight loss methods & 17 & $4.1(1.56)$ & $4.4(1.37)$ & 29 & $3.6(1.55)$ & $4.0(1.63)$ \\
\hline Surgical weight loss methods & 17 & $3.5(1.46)$ & $4.8(1.29)$ & 29 & $3.1(1.33)$ & $3.4(1.27)$ \\
\hline
\end{tabular}

Self-assessment ranging from 1 to 7 on a Likert Scale with $1=$ no knowledge and $7=$ very good knowledge about topics given in the questionnaire

$\left(F_{(1,44)}=10.5, p<.05\right)$ and group $\left(F_{(1,44)}=8.6, p<.05\right)$ and a marginal interaction group $\mathrm{x}$ time $\left(F_{(1,44)}=3.5, p<.07\right)$

There were no significant effect comparing both groups in knowledge about maintaining factors, restrictions because of obesity and weight loss methods suggesting no impact of the program on these knowledge variables (all $p>.10$ ).

Open answers to knowledge questions (objective measure) Table 5 shows the means and standard deviations of the coding from open answers to our knowledge questions (objective measure). Analyses (see Table 7) revealed significant effects for four of six variables: Number of concepts used (psychic and somatic factors causing obesity)

Table 5 Means and standard deviations (SD) of knowledge about aspects of obesity expressed in open answers in course and control group (objective measure)

\begin{tabular}{|c|c|c|c|c|c|c|}
\hline \multirow[t]{2}{*}{ Variable } & \multicolumn{3}{|c|}{ Seminar group } & \multicolumn{3}{|c|}{ Newspaper group } \\
\hline & $n$ & $\mathrm{t} 0 M(S D)$ & $\mathrm{t} 1 M(S D)$ & $n$ & $\mathrm{t} 0 M(S D)$ & $\mathrm{t} 1 M(S D)$ \\
\hline \multicolumn{7}{|l|}{ Psychic factors } \\
\hline Concepts & 16 & $0.2(.35)$ & $1.2(.72)$ & 29 & $0.3(.46)$ & $0.1(.32)$ \\
\hline Misconceptions & 16 & $0.0(.13)$ & $0.0(.13)$ & 29 & $0.5(1.01)$ & $0.3(.53)$ \\
\hline Technical terms & 17 & $0.1(.24)$ & $1.2(1.13)$ & 29 & $0.1(.26)$ & $0.1(.31)$ \\
\hline \multicolumn{7}{|l|}{ Somatic factors } \\
\hline Concepts & 17 & $1.4(1.32)$ & $1.8(.90)$ & 29 & $0.8(.81)$ & $1.0(.68)$ \\
\hline Misconceptions & 17 & $0.4(.62)$ & $0.1(.26)$ & 29 & $06(.78)$ & $0.5(.63)$ \\
\hline Technical terms & 17 & $0.1(.49)$ & $0.7(.86)$ & 29 & $0.1(.26)$ & $0.1(.26)$ \\
\hline
\end{tabular}

Number of correct answers (global concepts), wrong answers (misconceptions) and correct technical terms used in the answer 
and correct use of domain-specific technical terms (psychic and somatic factors, see coding displayed in Table 2). Concerning concepts about somatic factors a significant effect of group $\left(F_{(1,44)}=8.1, p<.05\right)$ with higher values at both t 0 and $t 1$ for the course group compared to the control group. Concerning concepts about psychic factors analyses revealed highly significant effects of group $\left(F_{(1,44)}=17.3, p<.01\right)$, time $\left(F_{(1,44)}=\right.$ $14.2, p<.01)$, and interaction of group $\mathrm{x}$ time $\left(F_{(1,44)}=35.4, p<.01\right)$ with increasing values from to to t 1 for the course group and decreasing values for the control group, while the initial values in the course group were lower than those of the controls. Concerning the correct use of domain specific technical terms for somatic factors analyses revealed significant effects for group $\left(F_{(1,44)}=9.0, p<.05\right)$, time $\left(F_{(1,44)}=7.2, p<.05\right)$, and interaction of group $\mathrm{x}$ time $\left(F_{(1,44)}=7.2, p<.05\right)$ with an increase of values for the course group and a decrease for the control group over time. Concerning the correct use of domain specific technical terms for psychic factors analyses revealed highly significant effects of group $\left(F_{(1,44)}=21.1, p<.01\right)$, time $\left(F_{(1,44)}=23.4, p<.01\right)$, and interaction of group $\mathrm{x}$ time $\left(F_{(1,44)}=\right.$ $20.7, p<.01)$ with increasing values for the course group only. There was no difference between groups at 0 but at $\mathrm{t} 1$. Concerning misconceptions values decreased in the course group, but not in the control group. Yet, analyses yielded no significant main and interaction effects.

Stigmatization tendency/attitudes Table 6 shows the means and standard deviations of stigmatization tendency according to the attitudes questionnaire. Analyses (see Table 7) revealed significant effects on the subscale "assignment of guilt" and "responsibility for health". Concerning assignment of guilt a significant effect of time $\left(F_{(1,44)}=7.2, p<.05\right)$ and interaction of group $\mathrm{x}$ time $\left(F_{(1,44)}=4.8, p<.05\right)$ with decrease of values for the course group from to to $\mathrm{t} 1$, while the control group remained on the same level over time. Concerning responsibility for health a significant effect of group $\left(F_{(1,44)}=5.5, p<.05\right)$ was found with lower values for the control group both at 0 and $\mathrm{t} 1$. The other subscales and the total score of the questionnaire did not yield significant differences between the groups.

In sum, analyses show significant differences between students who produced video clips and a control group of students who read a newspaper article on the topic. The course group assessed their own knowledge on causes of obesity and stigmatization higher in the

Table 6 Means and standard deviations of stigmatizing attitudes in course and control group

\begin{tabular}{|c|c|c|c|c|c|c|}
\hline \multirow[t]{2}{*}{ Variable } & \multicolumn{3}{|c|}{ Seminar group } & \multicolumn{3}{|c|}{ Newspaper group } \\
\hline & $n$ & $\mathrm{t} 0 M(S D)$ & $\mathrm{t} 1 M(S D)$ & $n$ & $\mathrm{t} 0 M(S D)$ & $\mathrm{t} 1 M(S D)$ \\
\hline Stigmatizing attitude-total score & 17 & $3.91(.72)$ & $3.73(.78)$ & 29 & $3.89(.81)$ & $3.94(.69)$ \\
\hline Subscale refusal and contact shunning & 17 & $4.16(.90)$ & $4.05(.81)$ & 29 & $4.32(.69)$ & $4.45(.86)$ \\
\hline Subscale assignment of guilt & 17 & $3.84(1.09)$ & $3.24(1.01)$ & 29 & $3.84(1.31)$ & $3.78(1.15)$ \\
\hline Subscale fat phobia & 17 & $5.49(1.12)$ & $5.45(1.24)$ & 29 & $5.85(1.10)$ & $5.95(.96)$ \\
\hline Subscale feature of performance & 17 & $2.42(.91)$ & $2.33(.94)$ & 29 & $2.68(1.36)$ & $2.86(1.47)$ \\
\hline Subscale responsibility for health & 17 & $3.63(1.06)$ & $3.55(1.09)$ & 29 & $2.76(1.54)$ & $2.64(1.46)$ \\
\hline
\end{tabular}

Attitude scores ranging from 1 to 7 on a Likert Scale with $1=$ low agreement and $7=$ high agreement to statements given in the questionnaire 
Table 7 Overview over results from mixed within-between ANOVAs

Knowledge items

\begin{tabular}{lllllll}
\hline & Within & & IA & \multicolumn{3}{c}{ Between } \\
Self-assessed knowledge: & $\mathrm{p}$ & $\mathrm{F}_{(1,44)}$ & $\mathrm{p}$ & $\mathrm{F}_{(1,44)}$ & $\mathrm{p}$ & $\mathrm{F}_{(1,44)}$ \\
Development of obesity, somatic aspects & $.035^{*}$ & 4.7 & $.024^{*}$ & 5.4 & n.s. & \\
Development of obesity, psychic aspects & $\mathrm{n} . \mathrm{s}$ & & $.028^{*}$ & 5.1 & n.s. & \\
Stigmatization because of obesity & $.004^{*}$ & 9.1 & $.004^{*}$ & 9.1 & $.001^{* *}$ & 13.8 \\
Mental comorbidities & n.s. & & .058 & 3.8 & $.047^{*}$ & 4.2 \\
Somatic comorbidities & n.s. & & .054 & 3.9 & $.003^{*}$ & 10.3 \\
Surgical weight loss methods & $.002^{*}$ & 10.5 & .067 & 3.5 & $.005^{*}$ & 8.6 \\
Coding from answers to knoweldge questions: & & & & & & \\
Somatic factors: concepts & .092 & 3.0 & n.s. & & $.007^{*}$ & 8.1 \\
Psychic factors: concepts & $.001^{* *}$ & 14.2 & $.001^{* *}$ & 35.3 & $.001^{* *}$ & 17.3 \\
Somatic factors: technical terms & $.010^{*}$ & 7.2 & $.010^{*}$ & 7.2 & $.004^{*}$ & 9.0 \\
Psychic factors: technical terms & $.001^{* *}$ & 23.4 & $.001 * *$ & 20.7 & $.001^{* *}$ & 21.1 \\
Somatic factors: misconceptions & .057 & & n.s. & & n.s. &
\end{tabular}

Attitudes

\begin{tabular}{lllllll} 
Subscale "assigned guilt" & $.010^{*}$ & 7.2 & $.033^{*}$ & 4.8 & n.s. & \\
Subscale "responsibility for health" & n.s. & & n.s. & & $.024^{*}$ & 5.5 \\
\hline
\end{tabular}

$* p<0.05 ; * * p<0.01$

post-test than the control group. Objective measures support the self-assessments and indicate substantial knowledge acquisition in the course group.

\section{Discussion}

Mobile phones and advanced web-based video tools have pushed forward new ways for using video in education. In this article we present video creation for YouTube as a method for learning through design (e.g., Kafai and Resnick 1996) in higher education. Concretely, video creation (which we have studied in our prior research) is suggested for acquiring complex knowledge about a controversial issue-obesity-which is widely discussed in the public media and which is not neutral but usually associated with strong negative attitudes. We present an educational concept structuring video creation in a study course into different steps that support students' collaborative design and learning processes. The concept is based on the assumption that development of knowledge about the complex nature of obesity can reduce possible stigmatization tendencies. We assume so, because one underlying mechanism of stigmatization may be misconceptions and oversimplification-thus introduction of complex knowledge and understanding should help in correcting misconceptions and in developing more differentiated knowledge and attitudes. In order to test the effectiveness of the concept, we compared in a field study within a quasi-experimental study design two groups of students: a course group where psychology students produced topic-related video clips during a study module on obesity (based on the learning through design methods) and a control group of psychology 
students who were provided with a newspaper article on the topic. Both groups were otherwise exposed to then normal everyday public media messages and debate on obesity.

Overall, the findings suggest an impact of course participation on knowledge and understanding. Our initial evidence indicates that the course program is successfully applicable in higher education. First, the resulting video clips evidenced that the students in the course group were highly successful in using video tools and finally creating impressive video clips. Thus they had acquired the respective media-related skills to present the topic for an audience. The anonymous evaluation by the university administration yielded positive results, too. So the students were highly satisfied with the course concept and their own course work. Second, significant differences in knowledge acquisition between the course group and controls across time on both subjective and objective knowledge assessments were found. Knowledge acquisition significantly increased in the course group, but not in the control condition. Differences between the course and control groups relate to students' complex understanding about psychic and somatic factors in obesity development and knowledge about stigmatization. Third, a corresponding significant reduction in stigmatization tendency was found in the course group (i.e., those students who acquired the new and more complex knowledge), but not in the control group.

These results are interpreted as initial confirmation of the efficacy of our educational concept and our underlying assumptions. The results are in line with social psychological lab research indicating that giving causal information can reduce stereotyping about obese people (Puhl et al. 2005; Teachman et al. 2003). Yet, the study is one of the few field studies that replicate such lab results in a real "noisy" educational setting.

Despite the strengths in ecological validity and results, the study has its limitations: Due to the quasi-experimental design, internal validity is limited. Randomization and a further control group that would receive a lecture on obesity over the course of the summer term were not possible. So we need further results that substantiate our assumptions. We think, however, the results are promising and hope to stimulate further field research-our own future studies aim at applying video creation as a method in schools with students younger than the ones participating in our present study.

Acknowledgments This project was funded by the Science Campus Tübingen, Germany, a research network funded by the federal state of Baden-Württemberg and the University of Tübingen in equal shares. (http://www.wissenschaftscampus-tuebingen.de)

\section{References}

Alby, T. (2007). Web 2.0: Concepts, applications, technologies. Munich: Hanser Fachbuchverlag.

Anderson, L. W., \& Krathwohl, D. R. (2001). A taxonomy for learning, teaching, and assessing: A revision of Bloom's taxonomy of educational objectives. New York: Longman.

Ata, R. N., \& Thompson, J. K. (2010). Weight bias in the media: a review of recent research. Obesity and the Facts, 3(1), 41-46.

Bandura, A. (2004a). Social cognitive theory for personal and social change by enabling media. In A. Singhal \& M. J. Cody (Eds.), Entertainment education and social change. Mahwah: Lawrence Erlbaum Ass.

Bandura, A. (2004b). Health promotion by social cognitive means. Health Education and Behavior, 31(2), $143-164$.

Baur, L. A. (2001). Obesity: definitely a growing concern. Medical Journal of Australia, 174, 553-554.

Bereiter, C., \& Scardamalia, M. (1987). The psychology of written composition. Hillsdale: Lawrence Erlbaum Associates. 
Burgess, J., \& Green, J. (2009). YouTube. Online video and participatory cultures. Digital media and society series. Cambridge (UK) Malden, (MA, USA): Polity.

Carver, S. M., Lehrer, R., Connell, T., \& Erickson, J. (1992). Learning by hypermedia design: issues of assessment and implementation. Educational Psychologist, 27(3), 385-404.

Cha, M., Kwak, H., Rodriguez, P., Ahn, Y., Moon, S. (2007). I Tube, you tube, everybody tubes: Analyzing the world's largest user generated content video system. In Proceedings of the Internet Measurement Conference (IMC), October 24-26 (pp. 1-14). San Diego CA, US.

Chavez, V., Israel, B., Allen, A. J., Floyd DeCarlo, M., Lichtenstein, R., Schulz, A., et al. (2004). A bridge between communities: video-making using principles of community-based participatory research. Health Promotion Practice, 5(4), 395-403.

Degner, J. (2006). Die indirekte Erfassung von Einstellungen gegenüber übergewichtigen Menschen mit dem affektiven Priming. [Indirect Measurement of attitudes toward overweight people by affective priming]. Kassel: Kassel University Press.

Degner, J., \&Wentura, D. (2005). Vorurteil oder Selbstbild? Implizite Einstellungen gegenüber übergewichtigen Menschen. [Prejudice or self-concept? Implicit attitudes toward overweight people]. Paper presented at the 10th Meeting of the Section of Social Psychology of the German Association of Psychology. Jena. 25.-28. Sep.

Deusinger, I. M. (1998). Die Frankfurter Körperkonzeptskalen (FKKS). Goettingen, Bern, Toronto, Seattle: Hogrefe Verlag.

Field, A. (2005). Discovering statistics using SPSS: Second edition. London, Thousand Oaks, New Delhi: Sage Publications.

Frank, C. (2010). Menschen, die alles Dicke haben [People that are fed up with everything]. Süddeutsche Zeitung, 24th Seoptember, 2010. Süddeutsche Zeitung GmbH.

Gaebel, W., Ahrens, W., Schlamann, P. (2010). Konzeption und Umsetzung von Interventionen zur Entstigmatisierung seelischer Erkrankungen: Empfehlungen und Ergebnisse aus Forschung und Praxis. [Conceptualizing and realizing interventions targeting de-stigmatization of mental disorders: Advice and results from research and practice]. Aktionsbündnis seelische Gesundheit.

Giel, K. E., Thiel, A., Teufel, M., Mayer, J., \& Zipfel, S. (2010). Weight bias in work settings - a qualitative review. Obesity and the Facts, 3(1), 33-40.

Giel, K. E., Zipfel, S., Alizadeh, M., Schaeffeler, N., Zahn, C., Wessel, D., et al. (2012). Stigmatization of obese individuals by human resource professionals: an experimental study. BMC Public Health, 12(1), 525-533.

Goel, V., \& Pirolli, P. (1992). The structure of design problem spaces. Cognitive Science, 16, 395-429.

Goldman, R. (2004). Video perspectivity meets wild and crazy teens: design ethnography. Cambridge Journal of Education, 2(4), 147-169.

Goldman, R. (2007). ORION ${ }^{\mathrm{TM}}$, an online digital video data analysis tool: Changing our perspectives as an interpretative community. In R. Goldman, R. D. Pea, B. Barron, \& S. Derry (Eds.), Video research in the learning sciences (pp. 507-520). Mahwah: Erlbaum Associates.

Greeno, J. (2006). Learning in activity. In R. K. Sawyer (Ed.), The Cambridge handbook of the learning sciences (pp. 79-96). New York: Cambridge University Press.

Harel, I. (1990). Children as software designers: a constructionist approach for learning mathematics. The Journal of Mathematical Behavior, 9, 3-93.

Haslam, D. W., \& James, W. P. (2005). Obesity. Lancet, 366, 1197-1209.

Hayes, J. R. (1996). A new framework for understanding cognition and affect in writing. In M. Levy \& G. E. Ransdell (Eds.), The science of writing: Theories, methods, individual differences, and applications. Mahwah: Erlbaum Associates.

Hays, W. L. (1980). Statistics for the social sciences. London: Holt.

Hennessey, S., \& Murphy, P. (1999). The potential for collaborative problem solving in design and technology. International Journal of Technology and Design Education, 9(1), 1-36.

Hilbert, A., \& Ried, J. (2009). Obesity in print: an analysis of daily newspapers. Obesity and the Facts, 2(1), 46-51.

Hussin, M., Frazier, S., \& Thompson, J. K. (2011). Fat stigmatization on YouTube: a content analysis. Body Image, 8(1), 90-92.

Jenkins, J. (2009). What happened before YouTube? In J. Burgess \& J. Green (Eds.), YouTube: Online video and participatory culture. Digital media and society series (pp. 109-125). Malden: Polity Press.

Jenkins, H., Clinton, K., Purushotma, R., Robison, A. J., Weigel, M. (2006). Confronting the challenges of participatory culture; Media education for the 21st century. An occasional paper on digital media and learning. (Retrieved in June '09 from: http://tinyurl.com/2uztw4).

Kafai, Y. B. (1996). Learning design by making games: Children's development of design strategies in the creation of a complex computational artifact. In Y. B. Kafai \& M. Resnick (Eds.), Constructionism in practice: Designing, thinking, and learning in a digital world (pp. 71-96). Mahwah: Erlbaum Press. 
Kafai, Y. B., \& Ching, C. C. (2001). Affordances of collaborative software design planning for elementary students' science talk. The Journal of the Learning Sciences, 10(3), 323-363.

Kafai, Y., \& Resnick, M. (1996). Constructionism in practice: Designing, thinking, and learning in a digital world. Mahwah: Lawrence Erlbaum.

Kolodner, J. L., Camp, P. J., Crismond, D., Fasse, B., Gray, J., Holbrook, J., Puntembakar, S., Ryan, M. (2003a). Problem-based learning meets case-based reasoning in the middle-school science classroom: putting learning by Design ${ }^{\mathrm{TM}}$ into practice. Journal of the Learning Sciences, 12(4), 495-548.

Kolodner, J. L., Gray, J., \& Fasse, B. B. (2003b). Promoting transfer through case-based reasoning: rituals and practices in learning by design classrooms. Cognitive Science Quarterly, 3(2), 183-232.

Krauskopf, K., Zahn, C., \& Hesse, F. W. (2012). Leveraging the affordances of YouTube: the role of pedagogical knowledge and mental models of technology functions for lesson planning with technology. Computers and Education, 58, 1194-1206.

Lehrer, R., Erickson, J., \& Connell, T. (1994). Learning by designing hypermedia documents. Hypermedia and multimedia in the schools. Computers in the Schools, 10, 227-254.

Maldonado, H., Lee, B., Klemmer, S., Pea, R. (2007). Patterns of collaboration in design courses: Team dynamics affect technology appropriation, artifact creation, and course performance. In Proceedings of CSCL-2007 (Computer-Supported Collaborative Learning) (pp. 486-495). Mahwah, NJ: Erlbaum Associates.

Mensink, G., Schienkiewitz, A., Scheidt-Nave, C. (2012). Übergewicht und Adipositas in Deutschland: Werden wir immer dicker? DEGS-Studie zur Gesundheit Erwachsener in Deutschland. [Overweight and obesity in Germany: Are we becoming fat? DGES Study on the health of adults in Germany. Robert Koch Institut.

Paul, T., \& Thiel, A. (2005). Eating disorder inventory-2. Goettingen, Bern, Toronto, Seattle, Oxford, Prag: Hogrefe Verlag.

Pea, R., \& Hoffert, E. (2007). Video workflow in the learning sciences: Prospects of emerging technologies for augmenting work practices. In R. Goldman, R. Pea, B. Barron, \& S. Derry (Eds.), Video research in the learning sciences (pp. 427-460). Mahwah: Lawrence Erlbaum.

Pea, R., Mills, M., Rosen, J., Dauber, K., Effelsberg, W., \& Hoffert, E. (2004). The DIVER ${ }^{\mathrm{TM}}$ project: interactive digital video repurposing. IEEE Multimedia, 11, 54-61.

Persky, S., \& Eccleston, C. P. (2010). Medical student bias and care recommendations for an obese versus non-obese virtual patient. International Journal of Obesity, 1-8.

Preiss, K., Brennan, L., \& Clarke, D. (2013). A systematic review of variables associated with the relationship between obesity and depression. Obesity Reviews. doi:10.1111/obr.12052.

Puhl, R. M., \& Brownell, K. D. (2001). Bias, discrimination, and obesity. Obesity Research, 9, 788-805.

Puhl, R. M., \& Heuer, C. A. (2010). Obesity stigma: important considerations for public health. American Journal of Public Health, 100(6), 1019-1028.

Puhl, R. M., Schwartz, M. B., \& Brownell, K. D. (2005). Impact of perceived consensus on stereotypes about obese people: a new approach for reducing bias. Health Psychology, 24(5), 517-525.

Roschelle, J. (1992). Learning by collaborating: convergent conceptual change. The Journal of the Learning Sciences, 2(3), 235-276.

Scardamalia, M., \& Bereiter, C. (2002). Knowledge building. Theory, pedagogy, and technology. In R. K. Sawyer (Ed.), Cambridge handbook of the learning sciences (pp. 97-115). Cambridge University Press.

Schwartz, D. L., \& Hartman, K. (2007). It's not television anymore: Designing digital video for learning and assessment. In R. Goldman, R. Pea, B. Barron, \& S. Derry (Eds.), Video research in the learning sciences (pp. 335-348). Mahwah: Lawrence Erlbaum Ass.

Sikorski, C., Luppa, M., Kaiser, M., Glaesmer, H., Schomerus, G., Konig, H. H., et al. (2011). The stigma of obesity in the general public and its implications for public health - a systematic review. [Research Support, Non-U.S. Gov't]. BMC Public Health, 11, 661-668.

Stahl, E., Finke, M., \& Zahn, C. (2006a). Knowledge acquisition by hypervideo design: an instructional program for university courses. Journal of Educational Multimedia and Hypermedia, 15(3), 285-302.

Stahl, E., Zahn, C., Schwan, S., \& Finke, M. (2006b). Knowledge acquisition by designing hypervideos: Different roles of writing during courses of "new media production". In L. Van Waes, M. Leijten, \& C. Neuwirth (Eds.), Writing and digital media (pp. 77-88). Oxford: Elsevier.

Teachman, B. A., Gapinski, K. D., Brownell, K. D., Rawlins, M., \& Jeyaram, S. (2003). Demonstrations of implicit anti-fat bias: the impact of providing causal information and evoking empathy. Health Psychology, 22(1), 68-78.

Webb, N., \& Palincsar, A. (1996). Group processes in the classroom. In D. C. Berliner, \& R. C. Calfee (Eds.), Handbook of educational psychology (pp. 841-873). Mahwah, NJ: Lawrence Erlbaum Ass. 
Wentura, D., \& Greve, W. (2005). Assessing the structure of self-concept: evidence for self-defensive processes by using a sentence priming task. Self and Identity, 4, 193-211.

Zahn, C., Krauskopf, K., Hesse, F. W., \& Pea, R. (2009). Participation in knowledge building "revisited": Reflective discussion and information design with advanced digital video technology. In C. O'Malley, D. Suthers, P. Reimann, \& A. Dimitracopoulou (Eds.), Computer supported collaborative learning practices: CSCL2009 conference proceedings (pp. 596-600). New Brunswick: International Society of the Learning Sciences (ISLS).

Zahn, C., Krauskopf, K., Hesse, F. W., \& Pea, R. (2010a). Digital video tools in the classroom: How to support meaningful collaboration and advanced thinking of students? In M. S. Khine \& I. M. Saleh (Eds.), New science of learning-cognition, computers and collaboration in education (pp. 503-523). New York, Heidelberg, London: Springer.

Zahn, C., Pea, R., Hesse, F. W., \& Rosen, J. (2010b). Comparing simple and advanced video tools as supports for collaborative design processes. The Journal of the Learning Sciences, 19(3), 403-440.

Zahn, C., Krauskopf, K., Hesse, F. W., \& Pea, R. (2012). How to improve collaborative learning with video tools in the classroom? Social vs. cognitive guidance for student teams. International Journal of Computer-Supported Collaborative Learning, 7(2), 259-284. 